\title{
Erratum to: Activation of protein kinase $C$ is required for AMPA receptor GluR1 phosphorylation at serine 845 in the dorsal striatum following repeated cocaine administration
}

\author{
Jeong Hwan Oh • Ju Hwan Yang • Sung Min Ahn • \\ BuHyun Youn • Byung Tae Choi • John Q. Wang • \\ Eun Sang Choe
}

Published online: 13 February 2013

(C) Springer-Verlag Berlin Heidelberg 2013

\section{Erratum to: Psychopharmacology}

$$
\text { DOI 10.1007/s00213-013-2968-1 }
$$

The original version of this article inadvertently contained a mistake. The Acknowledgments is missing.

Acknowledgements This work was supported by the Financial Supporting Project of Long-term Overseas Dispatch of PNU's Tenuretrack Faculty, 2011, KRF (20100016867) and the NIH grant (DA010355). The authors declare that there is no conflict of interest.

The online version of the original article can be found at http://dx.doi.org/ 10.1007/s00213-013-2968-1.

J. H. Oh · J. H. Yang · S. M. Ahn · B. Youn · E. S. Choe $(\bowtie)$

Department of Biological Sciences, Pusan National University,

Pusan 609-735, South Korea

e-mail: eschoe@pusan.ac.kr

B. T. Choi

Division of Meridian and Structural Medicine,

Pusan National University, Yangsan 626-870, South Korea

\section{J. Q. Wang $(\bowtie)$}

Department of Basic Medical Science, School of Medicine,

University of Missouri-Kansas City, Kansas City,

MO 64108, USA

e-mail: wangjq@umkc.edu 